\title{
'Emek', a Red and Very Early-ripening New Pomegranate Cultivar
}

\author{
Doron Holland', Irit Bar-Ya'akov, and Kamel Hatib \\ Unit of Deciduous Fruit Tree Sciences, Agricultural Research Organization, \\ Newe-Ya'ar Research Center, P.O. Box 1021, Ramat Yishay, 30095, Israel
}

Additional index words. arid climate, commercial orchards, Punica granatum

Early-ripening, red peel and flesh pomegranate cultivars with high-quality fruits, sweet or sweet-sour good taste, and soft seeds are mostly desired by growers and consumers. Emek cultivar bred in the Newe-Ya'ar Research Center is an early-ripening pomegranate (Punica granatum L., Punicaceae) cultivar characterized by a self-pollinating and selffertile medium-sized trained tree with a vigorous growth habit and good productivity. When matured, the fruits are medium to large-sized with appealing dark pink to red skin color, red juicy arils of sweet flavor, and good eating quality. 'Emek' ripens in Israel in mid- to late August, which is $\approx 6$ weeks before the wellknown cultivar Wonderful.

\section{Origin}

'Emek' was bred in the Newe-Ya'ar Research Center, located in the Yizre'el Valley, Israel. The objective of our continuous breeding program is to develop new cultivars endowed with high production of goodquality fruits with special attention to very early- and late-ripening cultivars. 'Emek' was originated from open pollination of the Israeli cultivar P.G.128-29, which is listed in the Israel Plant Gene Bank ( $<$ http://igb. agri.gov.il $/$ main/index. pl?page $=22>$ ) in the Newe-Ya'ar pomegranate living collection. Seedlings were planted in Newe-Ya'ar pomegranate orchard in 2001 . From $\approx 800$ seedlings tested, seedling no. 1/4 was selected in 2003 and named as 'Emek' in 2006. The orchard was planted on clay grumusol (vertisol) soil at an elevation of $\approx 100 \mathrm{~m}$ above sea level (lat. $32^{\circ} 42^{\prime} \mathrm{N}$, long. $35^{\circ} 11^{\prime} \mathrm{E}$ ). Yizre'el Valley is characterized by a Mediterranean subtropical climate with an average annual rainfall of $\approx 580 \mathrm{~mm}$ concentrated from November through March. Mean diurnal minimum temperature in January is $6{ }^{\circ} \mathrm{C}\left(43^{\circ} \mathrm{F}\right)$, and mean diurnal maximum temperature in July is $33^{\circ} \mathrm{C}\left(91^{\circ} \mathrm{F}\right)$. Asexual propagation by cuttings was first performed

Received for publication 7 Apr. 2014. Accepted for publication 6 May 2014.

We thank Mr. Baruch Bar-Tel and Mr. David Lahav for operating the registration of the cultivar in Israel and in various places in the world and The Chief Scientist of the Israeli Ministry of Agriculture \& Rural Development for financing the pomegranate breeding program.

${ }^{1}$ To whom reprint requests should be addressed; e-mailvhhollan@agri.gov.il. in February of 2006, and since planting, a detailed follow-up was done on the tree and the fruit characteristics in comparison with other pomegranate cultivars. The trees were grown on their roots and trained to four principal branches on a short trunk. Trees were irrigated and fertilized during the entire growing season as described in Holland et al.
(2009). The data obtained indicate that 'Emek' is mostly suitable for a commercial cultivar with respect to its ripening time, fruit quality, and yield. Since Nov. 2009, 'Emek' was registered in Israel under the terms of the Israeli Plant Breeders' Right Law 5733-1973 (registration no. 2921). Recently the Emek cultivar (referred to as P.G.218-229) was genotyped and compared with 104 different pomegranate accessions by using 480 single nucleotide polymorphism markers originated from the newly assembled pomegranate transcriptome data (Ophir et al., 2014). Approximately 50 ha of commercial 'Emek' orchards were planted in Israel at several locations (Fig. 1) and first fruits were marketed in the summer of 2013.

\section{Description of tree characteristics}

Vigor and growth habit. This is a deciduous shrub that naturally develops many

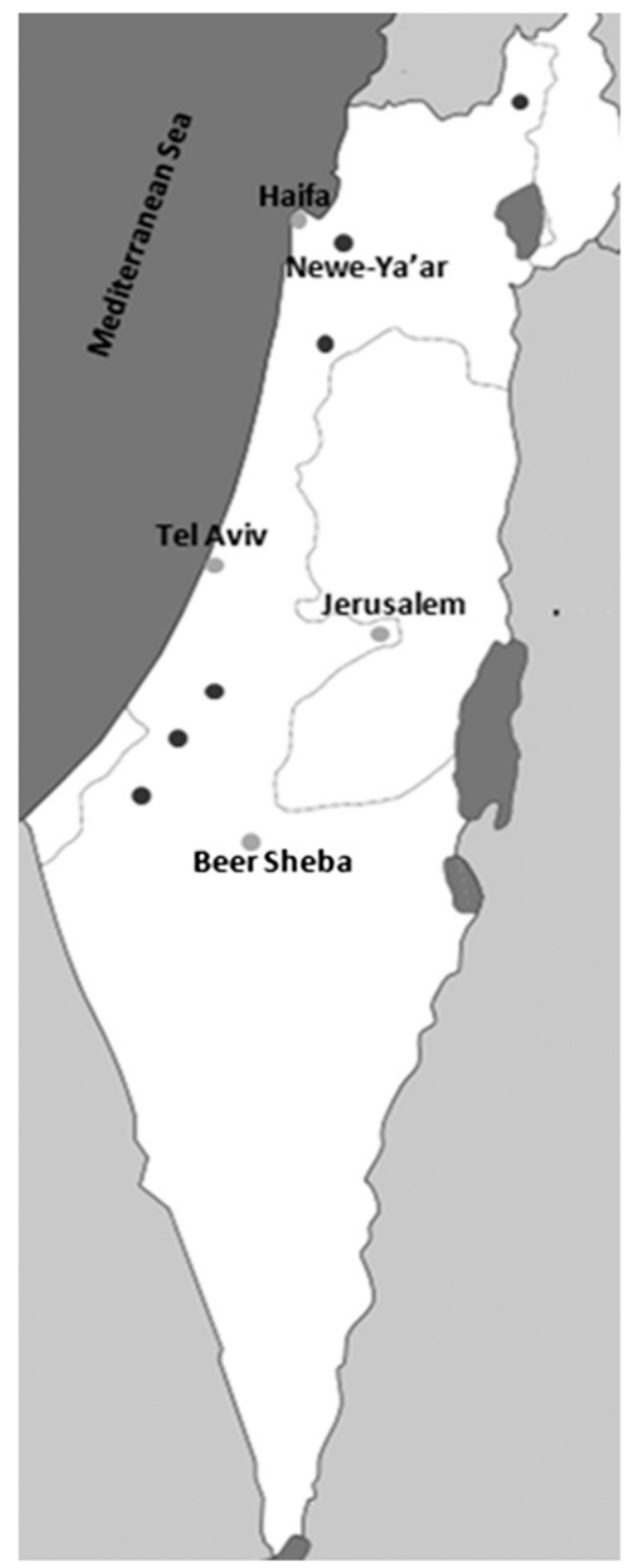

Fig. 1. Main commercial and experimental sites of 'Emek' orchards in Israel (dark point). 
trunks. A trained 'Emek' tree is of medium size, roundish, upright, and spreading in form (up to $3 \mathrm{~m}$ in height and $2.4 \mathrm{~m}$ in width). When trained on one trunk ( 50 to $60 \mathrm{~cm}$ up to leaders), leader branches angle up to $45^{\circ}$ with respect to the trunk. There are three or four leaders per tree, depending on pruning. The tree tends to develop suckers. It has good vigor, similar to 'Wonderful' and 'ShaniYonay' (Holland et al., 2007), and good growth intensity. On average, branches grow up to $2 \mathrm{~m}$ per growing season. Trunk texture is rough and bark color is brown [Royal Horticultural Society (RHS) N200C] and gray-brown (RHS199D). Colors match the RHS color chart (Royal Horticultural Society, 2001). Branches of new growth color are gray-brown (RHS 199) and mature is grayed green (RHS191A). The branches are thornless, excluding little thorns on young branches. These spines are brown-red (RHS 175A), $3 \mathrm{~mm}$ to $5 \mathrm{~mm}$ in length, and $\approx 1 \mathrm{~mm}$ width. Leaf budding is normal, during the first days of March, similar to 'Wonderful' and 'ShaniYonay'. Foliage is dense and vital. Leaves are opposed on the branches, arrange in pairs alternately crossing at right angles, extipulated, and petiolated. The petiole color is green (RHS 137C), $5.0 \pm 0.2 \mathrm{~mm}$ in length, and $\approx 1.0$ $\mathrm{mm}$ diameter. Fully developed leaf blades are entire and smooth, shape is oblanceolate, base shape is acuminate, and apex is obtuse. Venation is pinnate. Leaf shape is similar to that of 'Wonderful' and 'Shani-Yonay'. Leaf blades are $6.3 \pm 0.2 \mathrm{~cm}$ long and $2.2 \pm 0.1 \mathrm{~cm}$ wide. A young leaf blade's upper surface color is green (RHS 137A) and lower surface is green (RHS 144A-B). A mature leaf upper surface color is green (RHS 137A) and the lower surface is green (RHS 137C). Leaf fall occurs in November.

Pruning. The tree is trained on a single trunk up to 30 to $40 \mathrm{~cm}$ and then pruned to produce four main branches. From then on, winter pruning is done, mostly light, and removal of suckers during the growing season.

Propagation. Like most pomegranate cultivars, 'Emek' is propagated easily by rooting from cuttings. Frequency of rooting 'Emek' woody cuttings is high (almost 100\%). Scions of 'Emek' are also grafted easily on various pomegranate accessions as rootstocks. 'Emek' can also be rooted from green cuttings produced from young branches during the growing season.

Productivity. 'Emek' bearing habit is of a single or multiple fruits on newly developed growth. Thinning clusters of fruits are essential for reducing pest damage, physiological disorders, and scrubbing. In addition, controlling the total number of fruits per tree can increase fruit size. 'Emek' is a productive cultivar with an average yield of $52 \pm 10 \mathrm{~kg}$ / tree $\left(26 \mathrm{t} \cdot \mathrm{ha}^{-1}\right)$ for a 5- to 7-year-old trees. This is considered good productivity for early-ripening cultivars such as P.G.128-29 $\left(26 \mathrm{t} \cdot \mathrm{ha}^{-1}\right)$ and the late cultivar Wonderful P.G.101-2 (24 t.ha $\left.{ }^{-1}\right)$.

Disease sensitivity. No special sensitivity to insects or diseases was observed.

\section{Blooming}

'Emek' starts flowering in mid-April to the beginning of May and lasts $\approx 1$ month. In this feature, 'Emek' is similar to 'Wonderful' and 'Shani-Yonay'. Flowers on the same plant are present in various shapes, single or clustered. Fully developed flowers consist of hermaphrodite with fully developed reproductive organ flowers (vase-shaped), male flowers with poorly developed or undeveloped reproductive organs (bell-shaped), and variable stages between these two types. The sepals, five to seven, are fused in their base to form a red fleshy calyx with acute lobes. Vase shape flower calyx is a narrow funnel, $50 \mathrm{~mm}$ to $55 \mathrm{~mm}$ long and $31 \mathrm{~mm}$ to $43 \mathrm{~mm}$ in diameter. Calyx lobe length is 10 to $12 \mathrm{~mm}$ and width is 7 to $9 \mathrm{~mm}$. Its outer color is dark orange-red (RHS 33B) and the inner surface color is orange-red (RHS 33A). The petals, five to seven, are elliptic with a rounded apex and acute base and entire, undulated margins. They are very delicate, smooth, and a little wrinkled, like all other cultivars known to us. The orange-red (RHS 33B) petals emerge between the sepals alternately, 20 to $23 \mathrm{~mm}$ long and 17 to $20 \mathrm{~mm}$ wide. The stamens are numerous with 7 to $9 \mathrm{~mm}$ long dark orange (RHS 33A) filaments and yellow (RHS 4A) anthers. The single dark orange (RHS 32B) pistil, 5 to $7 \mathrm{~mm}$ long, of the fully developed flowers has a very small greenish yellow (RHS 1A) stigma at anther height or above them. The flowers have no fragrance.

Pollination requirements. 'Emek' is selffertile and self-pollinating.

\section{Fruit characteristics}

Ripening time. 'Emek' fruit ripens early and precedes that of 'Wonderful' by $\approx 6$ weeks and that of 'Shani-Yonay' and P.G.128-29 by 10 to $14 \mathrm{~d}$. Fruit ripen in the last third of August, the best eating quality phase. If not picked, fruit could last on the tree until October, but the eating quality deteriorates. In the western Negev, a hotter region than Newe-Ya'ar, it ripens a week earlier.

Fruit traits. The rounded, nearly uniform, and symmetrical fruit is slightly flattened near the stem end and has a prominent crown at the apex with half-closed lobes (Fig. 2). The average fruit circumference (widest point, right angle to axial plane) when picked is $30.9 \pm 0.8 \mathrm{~cm}$ and the average fruit weight is $411.8 \pm 25.5 \mathrm{~g}$. Under the same growth conditions, the average circumference of 'ShaniYonay' is $31.0 \pm 0.8 \mathrm{~cm}$ and the average weight is $413.6 \pm 30.1 \mathrm{~g}$ (Table 1). The peel is of medium thickness, quite similar to 'Wonderful', and thicker than 'Shani-Yonay'. The ripe fruit skin is smooth and shiny and its color is dark pink to red, uniformly spread over pinkish orange ground color. Aril weight is $\approx 0.37 \pm 0.02 \mathrm{~g}$ compared with $0.41 \pm 0.02 \mathrm{~g}$ for 'Wonderful'. The arils are eye-catching dark red (RHS 45A), juicy, and easily separated from the flashy mesocarp. 'Emek' flavor is sweet, non-astringent when picked and total soluble solids (TSS) are $\approx 14 \%$ compared with $16 \%$ to $18 \%$ for 'Wonderful' (Table 1$)$. The ovate seeds are small $(\approx 8 \mathrm{~mm}$ long, dry weight $\approx 0.024 \mathrm{~g}$ ) and relatively soft compared with those of 'Wonderful'. The septum is transparent and thin.

Fruit disorders. Sunburns are negligible on 'Emek' fruit like on 'Shani-Yonay' and much less compared with 'Wonderful', probably because of the early ripening season combined with the early red color development of the fruit. 'Emek' do not tend to crack, even when

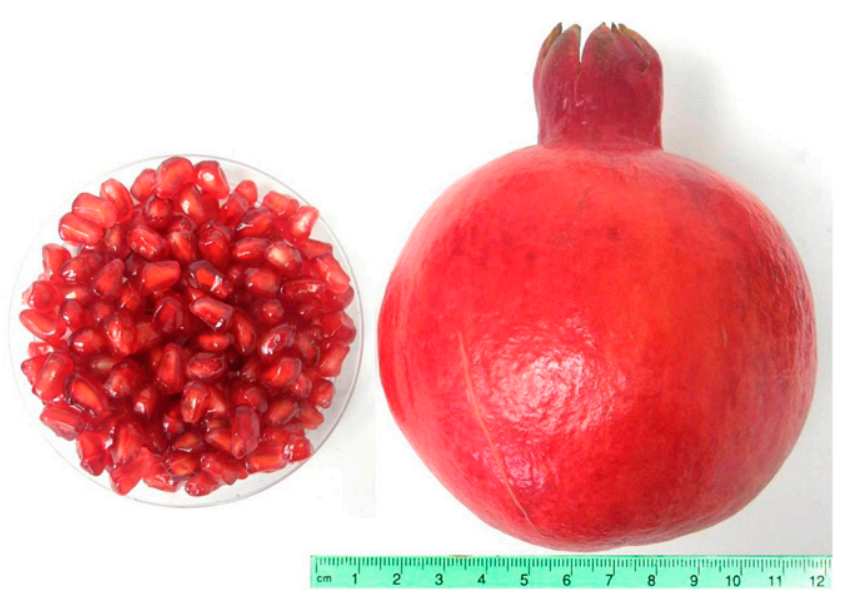

Fig. 2. 'Emek' fruit.

Table 1. Fruit characters of 'Emek' compared with early red maturing cultivars and with 'Wonderful' in Newe-Ya'ar.

\begin{tabular}{lcccccr}
\hline Cultivar & $\begin{array}{c}\text { Eating maturity } \\
\text { date }\end{array}$ & Fruit wt $(\mathrm{g})$ & Aril wt $(\mathrm{g})$ & $\begin{array}{c}\text { Seed } \\
\text { softness }\end{array}$ & Taste & TSS (\%) \\
\hline Emek & $20 / 8$ & 411.8 & 0.37 & Soft & Sweet & 14.3 \\
P.G.128-29 & $6 / 9$ & 364.3 & 0.32 & Soft & Sweet & 15.1 \\
Shani-Yonay & $2 / 9$ & 413.6 & 0.30 & Soft & Sweet & 14.7 \\
Wonderful & $9 / 10$ & 607.7 & 0.41 & Medium & Sweet sour & 16.4 \\
\hline
\end{tabular}

TSS $=$ total soluble solids. 
fruit is overripe. No special fruit sensitivity to insects or diseases was observed.

Fruit use. 'Emek' eating quality is very good. Pomegranate accessions from the Newe-Ya'ar collection were evaluated for their genetic diversity in flavor attributes of fresh arils. Between those accessions, 'Emek' (referred as P.G.218-229) was ranked among the most highly preferred arils (MayuoniKirshenbaum et al., 2013). There is no customary index for the picking time of 'Emek' pomegranate fruit. We consider the fruit of 'Emek' mature when the taste is sweet with no astringency; the arils are juicy and TSS is at least $13.0 \%$, although the fruit reaches an attractive skin and aril color earlier. The fruit can be marketed fresh and after a short cold storage. Trials are being conducted for elongating the storage period. 'Emek' can serve for consumption as fresh fruits, as packaged separated arils, or as juice.

\section{Availability}

'Emek' is registered under the terms of the Israeli Plant Breeders' Right Law 57331973, grant no. 2921 from 30 Nov. 2009. It was released for commercial use in Israel by a concessionary nursery and orchards were established already. Cuttings were received under appropriate contracts by applicators from several countries for testing and for commercial use. 'Emek' is registered in the United States as US PP21,907 P3 from 10 May 2011, in Peru granted as 0003782011 from 31 Mar. 2011, and in Argentina grant no. 3097 from 20 Dec. 2011. Applications were submitted in Europe (20072597), Chile (916), South Africa (PT6102), Australia (2011/114), and Brazil (21806.000250/2013). Nonindexed budwood is available pending concessions and a special contract through 'Kidum' R\&D Applications and Technology
Transfer Unit of the Agricultural Research Organization.

\section{Literature Cited}

Holland, D., K. Hatib, and I. Bar-Ya'akov. 2009. Pomegranate: Botany, horticulture, breeding, p. 127-191. In: Janick, J. (ed.). Horticultural Reviews 35(2). Wiley, NJ.

Holland, D., K. Hatib, I. Bar-Ya'akov, E. Yonay, and F. Abed Elhadi. 2007. 'Shani-Yonay' Pomegranate. Hortscience 42:710-711.

Mayuoni-Kirshenbaum, L., I. Bar-Ya'akov, K. Hatib, D. Holland, and R. Porat. 2013. Genetic diversity and sensory preference in pomegranate fruits. Fruits 68:517-524.

Ophir, R., A. Sherman, M. Rubinstein, R. Eshed, M. Sharabi Schwager, R. Harel-Beja, I. BarYa'akov, and D. Holland. 2014. Single-nucleotide polymorphism markers from de-novo assembly of the pomegranate transcriptome reveal germplasm genetic diversity. PLoS One 9:E88998.

Royal Horticultural Society. 2001. Color chart. Royal Horticultural Society, London, UK. 